\title{
Cysteine-, Methionine- and Seleno-Cysteine-Proline Chimeras: Synthesis and Their Use in Peptidomimetics Design
}

\author{
Azzurra Stefanucci ${ }^{1}$, Roberto Costante ${ }^{2}$, Giorgia Macedonio ${ }^{2}$, Szabolcs Dvoracsko $^{3}$ and Adriano Mollica ${ }^{2, *}$
}

${ }^{1}$ Dipartimento di Chimica, Sapienza, Università di Roma, P.le A. Moro 5, 00187 Rome, Italy;

${ }^{2}$ Dipartimento di Farmacia, Università di Chieti-Pescara "G. d'Annunzio", Via dei Vestini 31, 66100 Chieti, Italy; ${ }^{3}$ Institute of Biochemistry, Biological Research Centre, Hungarian Academy of Sciences, 6726, Szeged, Hungary

\begin{abstract}
Natural sulphurated amino acids are cysteine and methionine. Their importance in biological processes is largely known. Cysteine, plays a key role due to the thiol group, which represents a nucleophilic and easily oxidizable function. Synthetic methodologies to obtain Cysteine-, Methionineand Seleno-Cysteine-Proline chimeras are strongly desirable and particularly appealing in the field of organic chemistry.
\end{abstract}

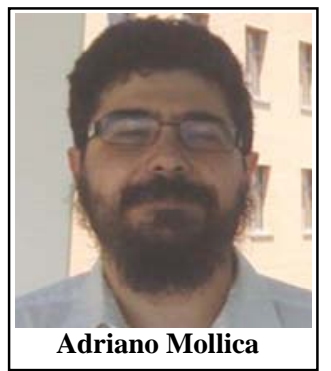

Keywords: Cysteine, methionine, seleno-cysteine proline chimeras, peptidomimetic design, $\chi$-Space, chemical ligation

\section{INTRODUCTION}

In proteins, free Cysteine (Cys) has a hydrophilic character, as hydrogen bond donor, while when covalently bonded each other, Cys residues have a crucial role in determining and stabilizing the conformation of protein and peptides [1, 2]. Methionine (Met) contributes to conformational properties of proteins through the Met-aromatic motif, a hydrophobic interaction that provides an additional stabilization [3].

Structure's modification on peptides is always responsible of changes in their biological activities, because a specific constraint, such as that imposed by unnatural amino acids, may destabilize the interactions between the ligand and the protein.

Methionine is an interesting amino acid residue in biologically active peptides; its conformationally constrained analogues are subdivided into two, well-documented classes (Fig. 1) [4-8].

Conformational profile of $N$-acetyl, $N$ '-methylamide derivatives of cis- and trans-3-methyl-proline shows an inverse $\gamma$-turn structure more stable than that of cis-3-methyl-proline [9], furthermore $\mathrm{C} \rightarrow \mathrm{C}^{\alpha}$ and $\mathrm{N} \rightarrow \mathrm{CO}^{\tau}$ cyclizations are two complementary constraints.

The $\beta$-stereocenter of proline amino acid determinates the amino acid side chain orientation in biologically active peptides binding to receptor [10].

To further delineate the molecular interactions of this $C$ terminal amino acid with both binding sites of the human NK1 tachykinin receptor, Sugase et al. [11] have designed

\footnotetext{
*Address correspondence to this author at the Dipartimento di Farmacia, Università di Chieti-Pescara "G. d'Annunzio", Via dei Vestini 31, 66100 Chieti, Italy; Tel: 0871-3554476; E-mail: a.mollica@unich.it
}

constrained analogs of methionine, i.e. 3-prolinomethionines. The resulting analogs completely lose NK-1 biological activity [12], a result which may come from the non-accurate fixed value of the $\chi^{2}$ angle on the pyrrolidine ring. In contrast, 3prolinoamino acids [13], combine the proline constraint on the peptide backbone (fixed $\chi^{1}$ angle) with the presence in position 3 (or $\beta$ ) on the pyrrolidine ring of the native amino acid side chain with a flexible $\chi^{2}$ angle.

Enomoto et al. [14] investigated the structural modifications of $N$-mercaptoacyl- $L$-proline and ( $4 R$ - $N$-mercaptoacylthiazolidine-4-carboxylic acid to build efficient leukotriene A4 $\left(\mathrm{LTA}_{4}\right)$ hydrolase inhibitors. The (2S)-3-mercapto-2methylpropionyl group was chosen for both of them (Fig. 2).

The insertion of 4-isopropylbenzylthio, 4-tertbutylbenzylthio or 4-cyclohexylbenzylthio group with $(S)$ configuration at the $\mathrm{C}-4$ position of proline, gave strong $\mathrm{LTA}_{4}$ hydrolase inhibitors.

The syntheses of 3-proline-methionine and 4-prolinemethionine chimeras have been performed via Zinc-enolate cyclization and Mitsunobu reaction in diastereoselective and enantioselective way (Fig. 3).

\section{3-SUBSTITUTED CYSTEINE-PROLINE AND ME- THIONINE-PROLINE CHIMERAS SYNTHESES}

\subsection{5-Exo-Trig-Cyclization via Zinc Enolate}

The first synthesis of a 3-proline-methionine chimera (3methylsulfanylmethyl-pyrrolidine-1,2-dicarboxylic acid dimethyl ester) has been described by Udding et al. [15] which involves xanthate transfer cyclization of a glycine radical, leading to non-regiospecific and non-diastereoselective reaction.

A more general strategy via Zinc-enolate cyclization, was reported by Karoyan and Chassing [16]. 
CLASS A:
$\int_{\mathrm{COOH}}^{\mathrm{S}_{2}^{\prime}}$

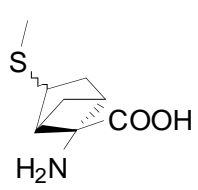
S
4-norbornanomethionine $\left(\mathrm{N}_{4}{ }^{\mathrm{Z}}\right.$ Met and $\mathrm{N}_{4}{ }^{\mathrm{E}}$ Met)

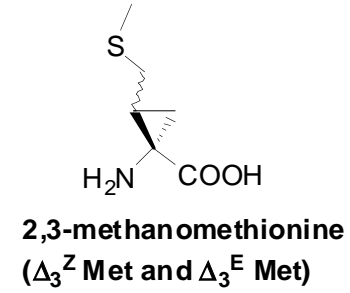
$(\alpha \mathrm{Me})$

CLASS B:<smiles>C[C@H]1CN[C@@H](C(=O)O)C1</smiles>

4-prolinomethionine ( $P_{4}{ }^{Z}$ Met and $P_{4}{ }^{E}$ Met)

Fig. (1). Conformationally constrained methionines.<smiles>[R]C(S)C([R2])C(=O)N1CCC[C@H]1C(=O)O</smiles><smiles>[R3]C(S)C([R2])C(=O)N1CSC[C@H]1C(=O)O</smiles>

Fig. (2). Structures of $N$-mercaptoacyl- $L$-proline and (4R)-Nmercaptoacylthiazolidine-4-carboxylic acid scaffolds.

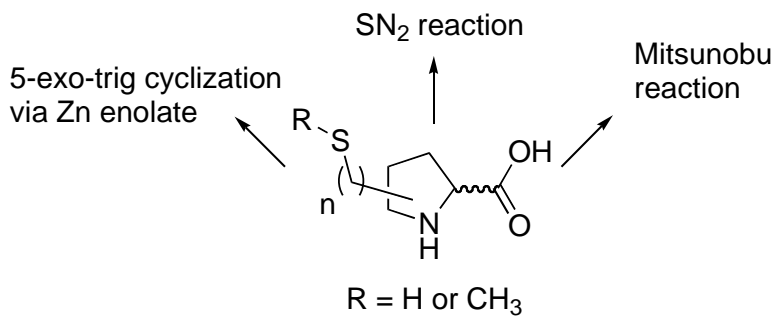

Fig. (3). Schematic representation of possible synthetic approaches to Met-Pro and Cys-Pro chimeras.

The organozinc derivative was treated with iodine to give ethyl cis-3-iodomethyl- $N$-benzylprolinate, which was alkylated by the sodium salt of methanethiol to yield the cis-3-prolinemethionine analogs as racemic mixture. A one-pot procedure could be also applied modifying the carbanionic species and using an electrophilic sulfur donor, so as the stereogenic center on the $\mathrm{N}$-protecting group generates an asymmetric C-2 carbon atom center.

Following Karoyan and Chassing also described the conversion of the $\mathrm{N}$-(o-methylbenzyl)-prolinomethionine into $\mathrm{N}$ (vinyloxycarbonyl)-prolinomethionine $\left(\operatorname{Voc}\left(\mathrm{P}_{3}\right) \mathrm{Met}\right)$, and into $N$-(tert-butoxycarbonyl)-prolinomethionine $\left(\mathrm{Boc}\left(\mathrm{P}_{3}\right) \mathrm{Met}\right)$ (Scheme 1) [17].

The $(-) /(+)$ [But-3-enyl-(1-phenyl-ethyl)-amino]-acetic acid ethyl or benzyl ester (-)-1 and (+)-1 were prepared by alkylation of (-) or (+)- $\alpha$-methylbenzylamine with 4-<smiles>CSC[C@H]1CCN[C@@H]1C(=O)O</smiles>

3-prolinomethionine $\left(P_{3}{ }^{Z}\right.$ Met and $P_{3}{ }^{E}$ Met) bromobutene and ethylbromoacetate or benzylbromoacetate respectively, in DMSO.

The lithium enolate of (-)-1 was transmetallated (3 eq. of dried $\mathrm{ZnBr}_{2}$ at $-90^{\circ} \mathrm{C}$ ) to yield cis diastereoselective cyclization, the reaction mixture was cooled to $0^{\circ} \mathrm{C}$ and the second transmetallation reaction was carried out (1.2 eq. of $\mathrm{CuCN}$ $1 \mathrm{M}, \mathrm{LiCl}$ in $\mathrm{THF}$ at $0^{\circ} \mathrm{C}$ for $10 \mathrm{~min}$.), then $(S)$-methyl methanesulfonothiolate was added.

Easy cleveage of the cuprozinc compound was achieved giving the 3-methyl-sulfanylmethyl-1-(1-phenyl-ethyl)-pyrrolidine-2-carboxylic acid ethyl ester 2 in $2 S, 3 R$ configuration.

Olofson et al. [18] used vinylchloroformate for $\mathrm{N}$ dealkylations on product $\mathbf{2}$, despite the slow reaction's rate, then voc group was removed from $\mathbf{3}$ by $\mathrm{HCl}$ in dioxane.

Tert-butoxycarbonyl ( $N$-Boc) protection and saponification gave $(2 S, 3 R)$-Boc 3-proline-methionine $\mathbf{4}$ as crude mixture, which was following purified by silica gel chromatography.

An alternative route was proposed starting from (+)- $\alpha$ methylbenzylamine to give $(2 R, 3 S)$-benzyl-Voc-3-prolinemethioninate $\mathbf{5}$, which was deprotonated by LDA in THF at $78{ }^{\circ} \mathrm{C}$ obtaining an inversion of configuration at the $\mathrm{C}^{\alpha}$ carbon over $90 \%$ (as determined by NMR).

Enantiomerically pure $(2 S, 3 S)$-benzyl-Voc-3-prolinemethioninate 6 was isolated after flash chromatography. $\mathrm{Boc}_{2} \mathrm{O}$ protection and saponification gave the $(2 S, 3 S)$-Boc 3proline-methionine 7.

As a continuation of their studies concerning solid-phase amino-Zinc-enolate cyclization, Karoyan et al. [19] explored the iodo derivative $\mathbf{8}$ functionalization (Scheme $\mathbf{2}$ ).

Compound $\mathbf{8}$ was reacted with two kinds of nucleophiles sodium thiophenate and $p$-nitrophenol in $\mathrm{DMF}$, at $50^{\circ} \mathrm{C}$. In the first case, compound $\mathbf{1 0}$ was characterized by mass spectroscopy after cleavage of $\mathbf{9}$ from the resin while in the second case, 2 eq. of nucleophile were used with $\mathrm{K}_{2} \mathrm{CO}_{3}$ giving nucleophilic substitution of the halogen atom and cleavage of the product from the resin. 


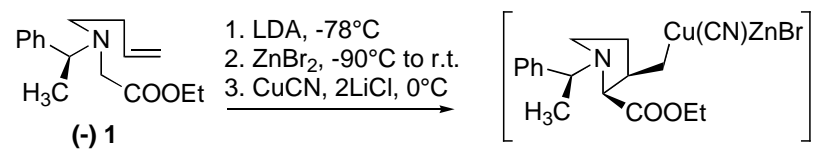

(-) 1
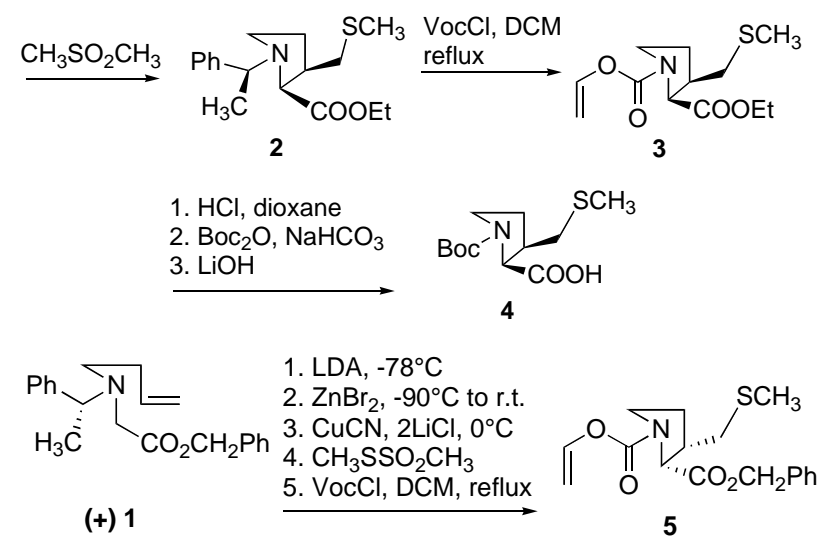

$\stackrel{\mathrm{LDA}, \mathrm{H}^{+},-78^{\circ} \mathrm{C}}{\longrightarrow} \pi_{\mathrm{O}}^{\mathrm{O}} \prod_{6}^{\mathrm{N}} k_{\mathrm{CO}_{2} \mathrm{CH}_{2} \mathrm{Ph}}^{\mathrm{SCH}_{3}}$

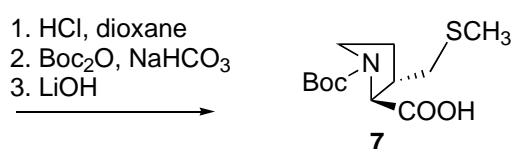

Scheme 1. Synthesis of $(2 S, 3 R)$ - and $(2 S, 3 S)$-prolinomethionine [17].

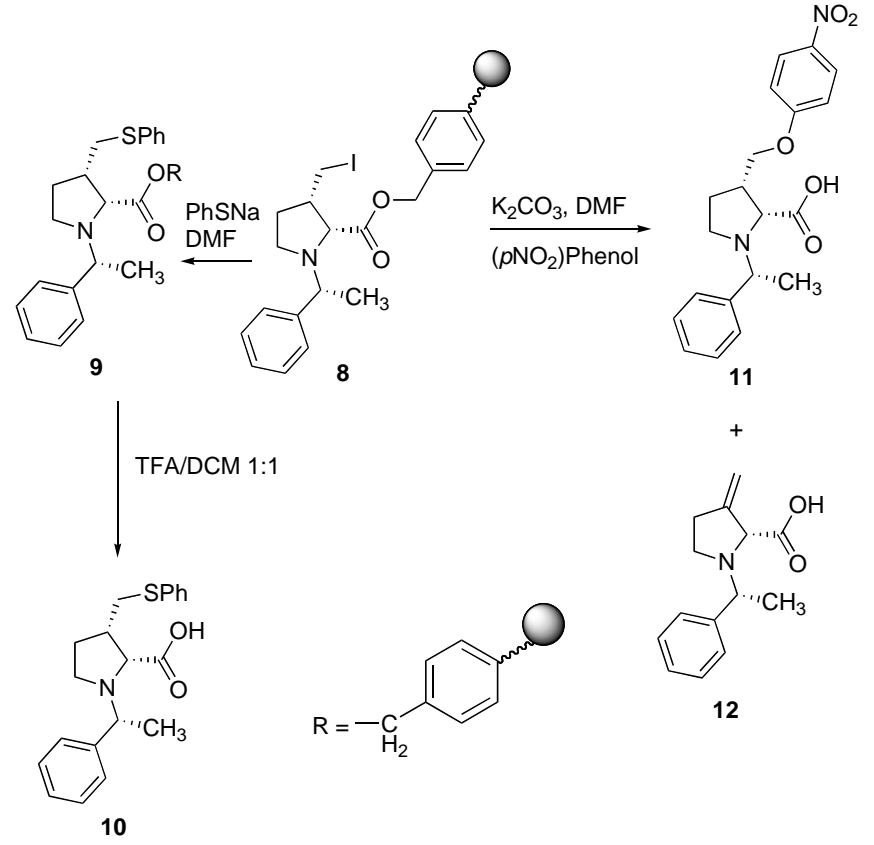

Scheme 2. Functionalization of the iodo derivative [19].

Basic conditions applied during the work-up of the reaction cleaved the $p$-nitrophenol ester providing compounds $\mathbf{1 1}$ and $\mathbf{1 2}$.

\subsection{Via Dihydroproline Intermediate Formation}

Kolodziej et al. [20] reported the synthesis of protected cysteine-proline chimeras to the synthesis of $D, L-N$-Boc-3mercapto-proline (D,L-15) (Scheme 3).
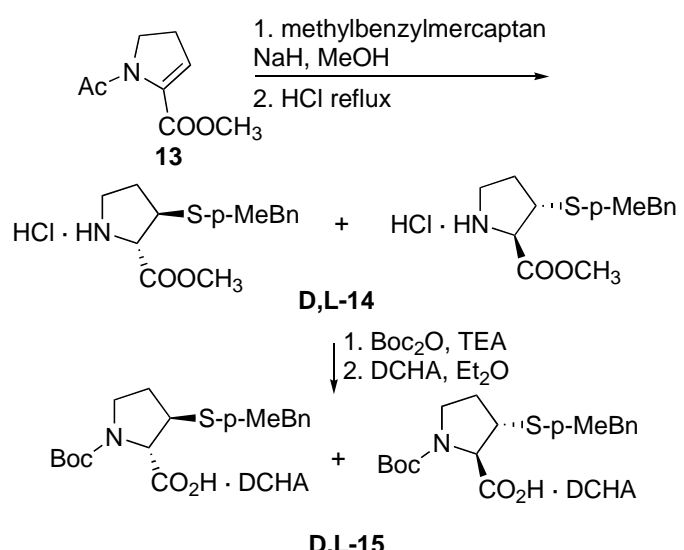

Scheme 3. Synthesis of 3-substituted proline reported by Kolodziej et al. [20].

Conjugate addition of 4-methylbenzylmercaptan to 2,3dehydroproline derivative 13, [21] and hydrolysis in acid conditions, provided the trans-diastereomer $\mathbf{1 4}$ following ripetitive crystallizations, in 52\% yield. Compound 14 was protected with $\mathrm{Boc}_{2} \mathrm{O}$ to give derivative $\mathbf{1 5}$ as cyclohexylamine salt in $92 \%$ yield. In a similar manner, the cis-isomers were also obtained (Scheme 4).
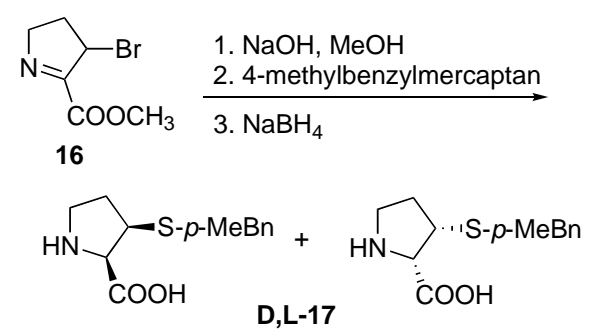

1. $\mathrm{Boc}_{2} \mathrm{O}, \mathrm{TEA}$

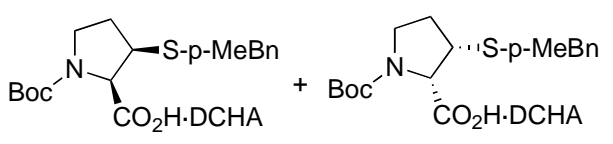

D,L-18

Scheme 4. Synthesis of diastereomeric mixture of protected 3substituted proline [20].

The 3-bromo-1,2-dehydroproline derivative 16 was described by Hausler and Schmidt [22], and used to react with 4-methylbenzylmercaptan in aqueous sodium hydroxide; diastereoselective reduction with $\mathrm{NaBH}_{4}$ provided the cisisomer $D, L-17$ in an overall yield of $37 \%$.

\section{4-SUBSTITUTED CYSTEINE-PROLINE AND ME- THIONINE-PROLINE CHIMERAS SYNTHESES}

\subsection{Mitsunobu Reaction}

Selective CCK-B agonist can be prepared by substitution of the ${ }^{31}$ Met residue in Boc-CCK4 ((Boc-Trp ${ }^{30}-\mathrm{Met}^{31}-\mathrm{Asp}^{32}$ 


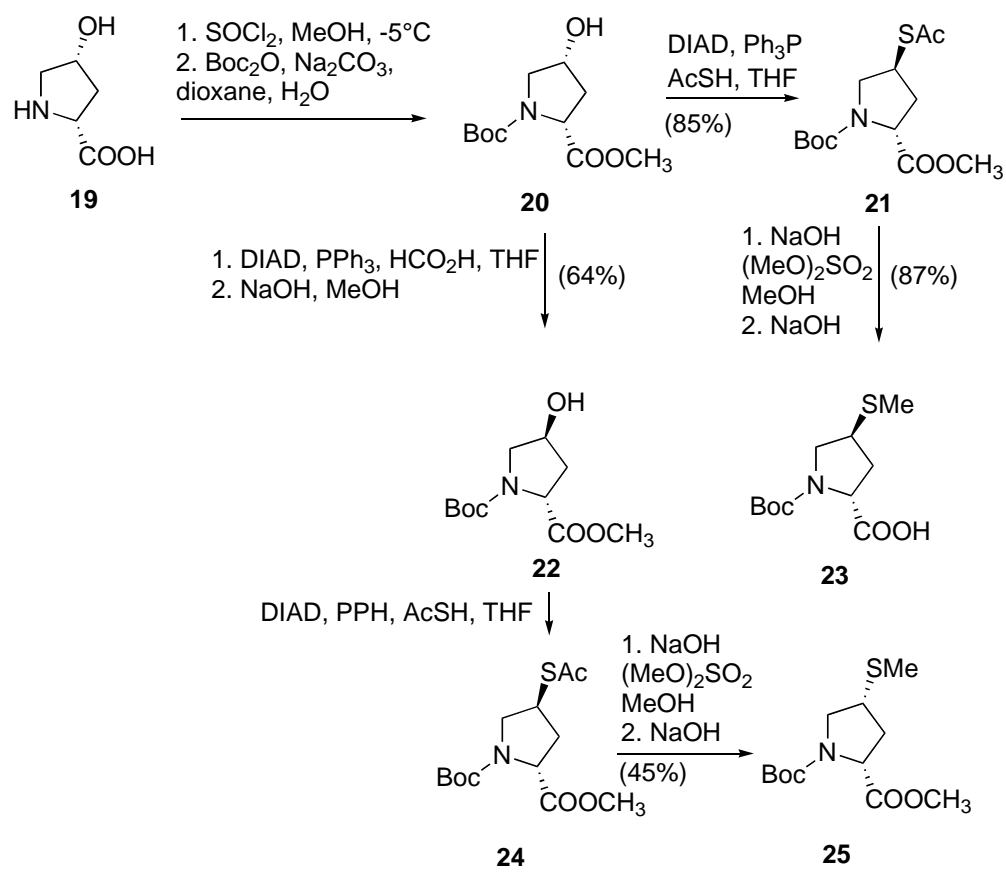

Scheme 5. Synthesis of 4-substituted Cys-Pro reported by Kolodziej et al. [20].

$\mathrm{Phe}^{33}-\mathrm{NH}_{2}$ ) with trans-3-propyl-proline. At this regard, Kolodziej et al. [20] synthesized different Ac-CCK4 analogs containing 3- and 4-(alkylthio)-substituted proline derivatives. A high-yielding synthetic strategy was developed to achieve the $S$-methylated derivatives 23 and 25 (Scheme 5).

Reaction of compound $\mathbf{2 0}$ with thiolacetic acid under Mitsunobu conditions is the key transformation, to provide derivative $\mathbf{2 1}$ in $85 \%$ yield [23].

Derivative 23 was obtained in a one-pot reaction's sequence [23] involving two selective hydrolysis and alkylation, in $60 \%$ overall yield from 19. Mitsunobu inversion of the $\mathrm{C}-4$ carbon of $\mathbf{2 0}$ was performed using formic acid, followed by hydrolysis of the formate ester to yield 22 in $64 \%$. Then $\mathbf{2 5}$ was obtained in an overall yield of $45 \%$ from $\mathbf{1 9}$, following the reaction's sequence described above. Recently Mollica et al. [24] investigated new fMLF analogs incorporating chimeric $L$-proline-methionine residues, namely the homochiral cis-4(S)-methylthio-(S)-proline $\mathbf{2 8}$ and the heterochiral trans-4(R)-methylthio- $(S)$-proline 35, in which $\gamma$ thiomethyl-ether functionality is preserved. Cis- and trans-4methylthio-proline derivatives can be prepared following different approaches [25].

To obtain $N$-Boc-cis-4(S)-methylthio- $(S)$-proline 28 and $N$-Boc-trans-4(R)-methylthio- $(S)$-proline 35, the $N$-protected cis-analog 28 was prepared from 4-hydroxy-trans-proline $\mathbf{2 9}$ treating the corresponding $N$-Boc-trans-4-mesylate 26 with potassium thioacetate, followed by hydrolysis of the derivative 27 and alkylation of the thiol group (Scheme 6).

The $N$-Boc derivative 29 was prepared to build $N$-Boctrans-analog 34 (Scheme 7).

In this case, two configurational inversions at C-4 occurred; the first involved the formation of the 4-oxo-analog 30 which, after stereoselective reduction with $\mathrm{NaBH}_{4}$, gave the $N$-Boc- $(2 S, 4 S)$-cis-isomer 31.

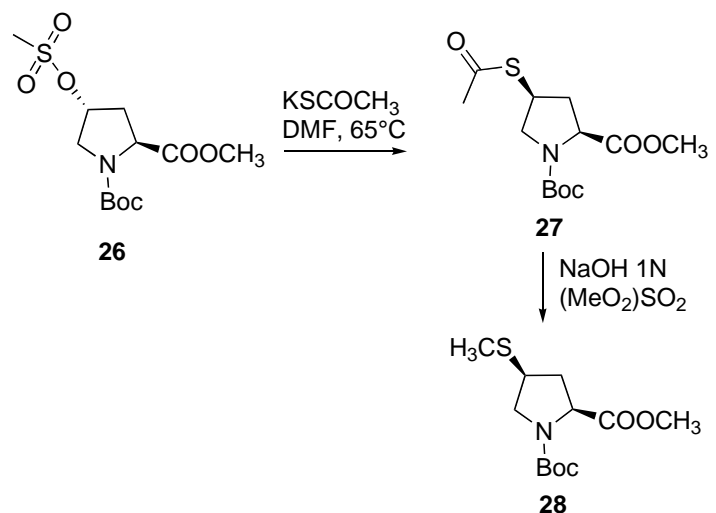

Scheme 6. Synthesis of cis-4(S)-methylthio-(S)-proline by Mollica et al. [24].

\section{4-SELENO-CYSTEINE-PROLINE CHIMERAS SYNTHESES}

\subsection{Mitsunobu Reaction}

The preparation of Seleno-Cysteine-Pro chimeras is particularly interesting since its use in native chemical ligation (NCL) in several papers [26-29].

One of the first attempt to synthesize these chimeras was done by Rüeger and Benn for the $(S)$-3,4-dehydroproline starting from $(2 S, 4 R)$-4-hydroxyproline [30], considering that selenoxide elimination can be regioselective if the required 3-ene function could be introduced (Scheme 8).

This protocol was applied successively by Robinson et al. [31] for the synthesis of a series of epoxyprolines and aminohydroprolines.

For this purpose, 3,4-dehydro- $L$-proline derivative was prepared from trans-hydroxy-L-proline $\mathbf{3 7}$ using a modified version of the method reported by Rüeger and Benn (Scheme 9) [30]. 


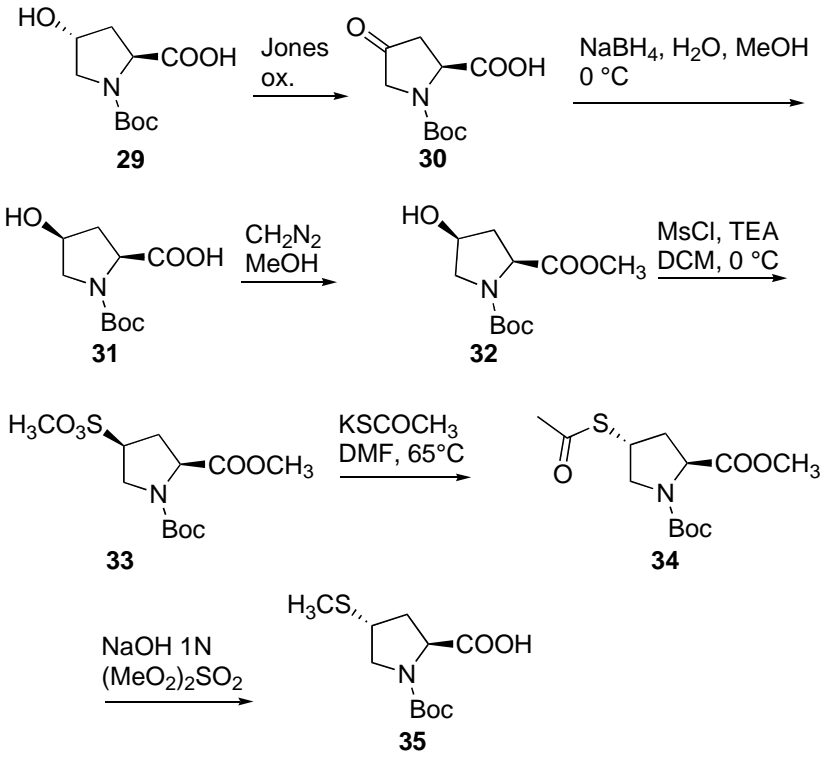

Scheme 7. Synthesis of trans-4(R)-methylthio-(S)-proline [24].

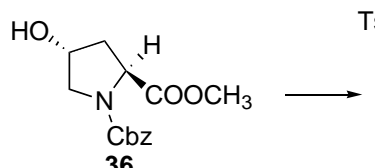

36

PhSe,

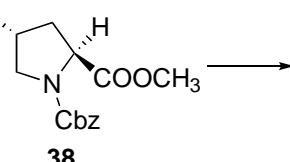

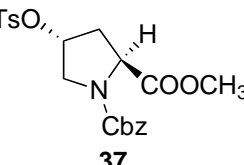

37

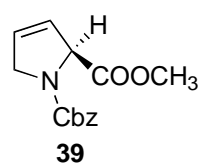

Scheme 8. Schematic representation of protocol applied by Rüeger and Benn [30].

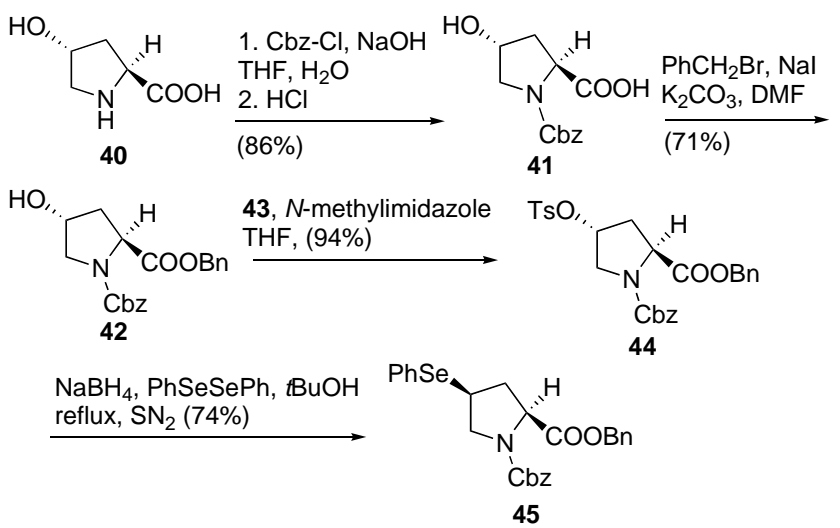

Scheme 9. Synthesis of intermediate product for Rüeger's procedure [30].

Treatment of derivative $\mathbf{4 2}$ with tosyl chloride/pyridine failed to give tosylate 44 in good yield. Then 1(toluenesulphonyl)-3-methylimidazolium triflate 43 was chosen to prepare product $\mathbf{4 4}$ in acceptable yield. Reaction of $\mathbf{4 4}$ with $\mathrm{PhSeSePh} / \mathrm{NaBH}_{4}$ in tert-butanol furnished 45 without transesterification. Durek and Alewood have studied the conversion of thioesters to selenoesters to give highly reactive $C$-terminal ligation partners [32]. Also Metanis et al.

[33] have described the ligation and the deselenization of peptide-feature $N$-terminal selenocysteine residues. Thus trans-seleno-proline, was synthesized for the first time (Scheme 10).

46
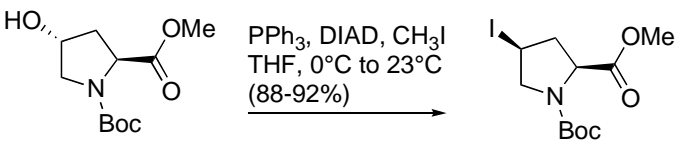

47 BzSeH, DIPEA DMF, $60^{\circ} \mathrm{C}(84 \%)$
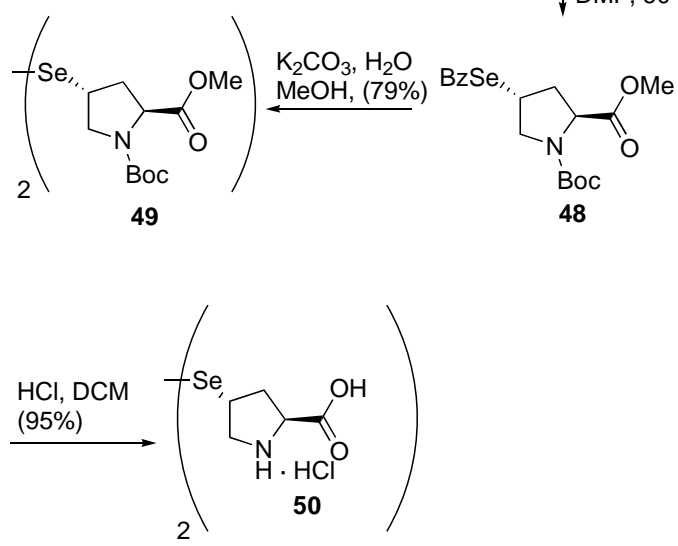

Scheme 10. Synthesis of trans-seleno-proline [30].

Beginning with the commercially available pyrrolidine 46, Mitsunobu inversion gave the cis-iodo-proline 47, in good yield. Treatment with selenobenzoic acid provided compound 48 in $84 \%$ yield. Removal of the benzoate and saponification occurs in concert to give $\mathrm{N}$-Boc selenoproline dimer 49 , in $79 \%$ yield which was finally removed under acidic conditions to afford oxidatively dimerized $\mathbf{5 0 .}$

\section{2. $\mathrm{S}_{\mathrm{N}} 2$ Reaction}

Starting from 4-hydroxylproline, Caputo et al. [34] reported a new procedure to prepare sulphur and selenium containing bis $\alpha$-amino acids. The existing hydroxyl group of trans-4-hydroxy- $L$-proline was involved in $\mathrm{S}_{\mathrm{N}} 2$ process, for which inversion of C-4 configuration occurred. Although trans configuration was maintained transforming the hydroxyl group either into its tosyl ester or by substitution with an iodine complex, giving the cis-4-iodo- $L$-proline. Cysteinyl nucleophile attack provided trans-4- $(S)$-cysteinyl- $L$-proline 53 from compound 51 and cis-4-(S)-cysteinyl-L-proline 54 from derivative 52; diastereomeric trans/cis 4-selenocysteinyl- $L$ prolines $\mathbf{5 5}$ and $\mathbf{5 6}$ were finally obtained with the addition of selenocysteinyl nucleophile (Scheme 11) [35].

\section{CONCLUSION}

This review is focused on Met, Cys, and Cys-Seleno Proline chimeras. The most important synthetic strategies reported in literature to prepare these chimeric compounds have been reported and discussed. They are particularly important in peptidomimetics design; for example, Wiśniewski reported a small library of oxytocin analogues [36], which show selectivity to vasopressin receptors and present several chemical modification, including the introduction of trans-4SMe-Pro residue in peptide 57 (Fig. 4). 


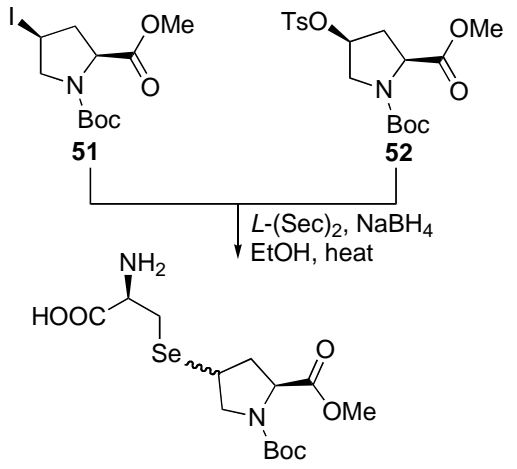

53-54

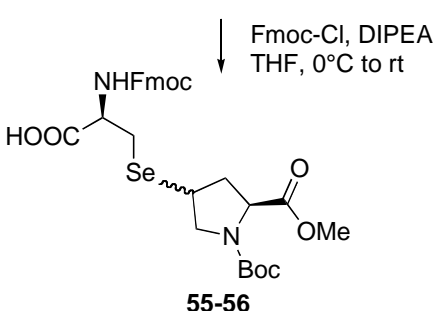

$55-56$

Scheme 11. Synthesis of bis $\alpha$-amino acids from 4-hydroxylproline by Caputo et al. [34].

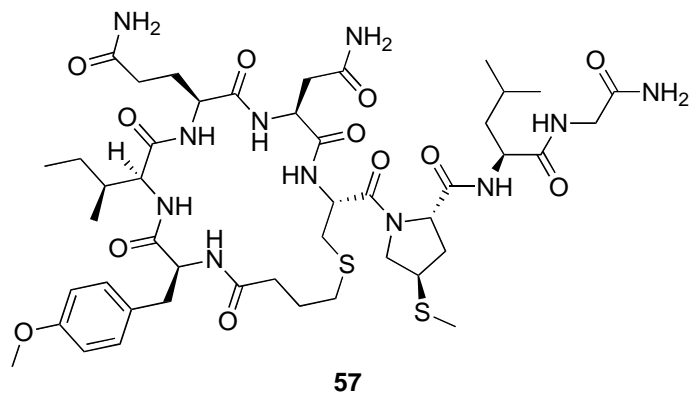

Fig. (4). An oxytocin analog containing a Met-Pro chimera residue [36].

This class of compounds can be considered central in the field of peptide-based drug discovery [37], due to the remarkable effects of proline and cysteine on peptides secondary structures.

\section{CONFLICT OF INTEREST}

The authors confirm that this article content has no conflict of interest.

\section{ACKNOWLEDGEMENTS}

Declared none.

\section{REFERENCES}

Pinnen, F.; Sozio, P.; Cacciatore, I.; Cornacchia, C.; Mollica, A.; Iannitelli, A.; D’Aurizio, E.; Cataldi, A.; Zara, S.; Nasuti, C.; Di Stefano, A. Ibuprofen and glutathione conjugate as a potential therapeutic agent for treating Alzheimer's disease., http://www.ncbi.nlm.nih.gov/pubmed/21384412 2011, 344, 139148.
$[2$

Trivedi, M.V.; Laurence, J.S.; Siahaan, T.J. The role of thiols and disulfides in protein chemical and physical stability. Curr. Protein Pept. Sci., 2009, 10, 614-625.

Valley, C.C.; Cembran, A.; Perlmutter, J.D.; Lewis, A.K.; Labello, N.P.; Gao, J.; Sachs, J.N. The Methionine-aromatic Motif Plays a Unique Role in Stabilizing Protein Structure. J. Biol. Chem., 2012 287, 34979-34991.

Burgess, K.; Ho, K.-K.; Pal, B. Comparison of the Effects of (2S,3S)-2,3-Methanomethionine,(2R,3R)-2,3-Methanomethionine, and (2R,3R)-2,3-Methanophenylalanine on the Conformations of Small Peptides. J. Am. Chem. Soc., 1995, 117, 3808-3819.

[5] Fantin, G.; Fogagnolo, M.; Guerrini, R.; Marastoni, M.; Medici, A.; Pedrini, P. Conformationally constrained amino acids: A concise route to a methionine analogue. Tetrahedron, 1994, 50, 12973 12978 .

[6] Steffen, L.K.; Glass, R.S.; Sabahi, M.; Wilson, G.S.; Schöneich, C. Mahling, S.; Asmus, K.-D. J. Am. Chem. Soc., 1991, 113, $2141-$ 2145.

[7] Barone, V.; Fraternali, F.; Cristinziano, P.L.; Lelj, F.; Rosa, A. Conformational behavior of $\alpha, \alpha$-dialkylated peptides: $A b$ initio and empirical results for cyclopropylglycine. Biopolymers, 1988, 27, 1673-1685.

[8] Benedetti, E.; Di Blasio, B.; Pavone, V.; Pedone, C.; Santini, A.; Crisma, M.; Valle, G.; Toniolo, C. Structural versatility of peptides from $\mathrm{C} \alpha, \alpha$ dialkylated glycines: Linear Ac3c homo-oligopeptid. Biopolymers, 1989, 28, 175-184.

[9] Delaney, N.G.; Madison, V. Novel Conformational Distributions of Methylproline Peptides. J. Am. Chem. Soc., 1982, 104, 6635-6641.

[10] Karoyan, P.; Chassaing, G. Asymmetric synthesis of (2S,3S)- and (2S,3R)-3-prolinomethionines:3-methylsulfanylmethyl-pyrrolidine2-carboxylic acids. Tetrahedron: Asymmetry, 1997, 8, 2025-2032.

[11] Sugase, K.; Horikawa, M.; Sugiyama, M.; Ishiguro, M. Restriction of a Peptide Turn Conformation and Conformational Analysis of Guanidino Group Using Arginine-Proline Fused Amino Acids: Application to Mini Atrial Natriuretic Peptide on Binding to the Receptor. J. Med. Chem., 2004, 47, 489-492.

[12] Blaney, P.; Grigg, R.; Rankovic, Z.; Thornton-Pett, M.; Xu, J. Fused and bridged bi- and tri-cyclic lactams via sequential metalloazomethine ylide cycloaddition-lactamisation. Tetrahedron, $\mathbf{2 0 0 2}$, 58, 1719-1737

[13] Schedler, D.J.A.; Godfrey, A.G.; Ganem, B. Reductive deoxygenation by $\mathrm{Cp}_{2} \mathrm{ZrHCl}$ : Selective formation of imines via zirconation/hydrozirconation of amides. Tetrahedron Lett., 1993, 34, 5035-5038.

[14] Enomoto, H.; Morikawa, Y.; Miyake, Y.; Tsuji, F.; Mizuchi, M. Suhara, H.; Fujimura, K.; Horiuchi, M.; Ban, M. Synthesis and biological evaluation of $N$-mercaptoacylproline and $N$ mercaptoacylthiazolidine-4-carboxylic acid derivatives as leukotriene $\mathrm{A}_{4}$ hydrolase inhibitors. Bioorg. Med. Chem. Lett., 2008, 18 , 4529-4532.

[15] Udding, J.H.; Tuijp, C.J.M.; Hiemstra, H.; Speckamp, W.N. Transition metal-catalyzed chlorine transfer cyclizations of carboncentered glycine radicals; A novel synthetic route to cyclic $\alpha$-amino acids. Tetrahedron, 1994, 50, 1907-1918.

[16] Vaupel, A.; Knochel, P. Stereoselective Synthesis of Heterocyclic Zinc Reagents via a Nickel-Catalyzed Radical Cyclization. J. Org Chem., 1996, 61, 5743

[17] Karoyan, P.; Chassaing, G. New Strategy for the Synthesis of 3Substituted Prolines. Tetrahedron Lett., 1997, 38, 85-88.

[18] Olofson, R.A.; Schnur, R.C.; Bunes, L.; Pepe, J.P. Selective Ndealkylation of tertiary amines with vinyl chloroformate: An improved synthesis of naloxone. Tetrahedron Lett., 1977, 18, 15671570 .

[19] Karoyan, P.; Triolo, A.; Nannicini, R.; Giannotti, D.; Altamura, M.; Chassaing, G.; Perrotta, E. Solid-Phase Amino-Zine-Enolate Cyelizationfor the Synthesis of 3-Substituted Prolines. Tetrahedron Lett. 1999, 40, 71-74

[20] Kolodziej, S.A.; Nikiforovich, G.V.; Skeean, R.; Lignon, M.F.; Martinez, J.; Marshall, G.R. Ac-[3- and 4-Alkylthioproline $\left.{ }^{31}\right]$ $\mathrm{CCK}_{4}$ Analogs: Synthesis and Implications for the CCK-B Receptor-Bound Conformation. J. Med. Chem., 1995, 38, 137-149.

[21] Häusler, J. Darstellung von cis- und trans-C-3-substituierten Prolinverbindungen. Liebigs Ann. Chem., 1981, 6, 1073-1088.

[22] Häusler, J.; Schmidt, U. Synthese von cis- und trans-3Phenoxyprolin. Liebigs Ann. Chem., 1979, 11, 1881-1889. 
[23] Lago, M.A.; Samanen, J.; Elliott, J.D. Enantioselective routes to protected syn- and anti-.beta.-phenylcysteines. J. Org. Chem., 1992, 57, 3493-3496.

[24] Mollica, A.; Paglialunga Paradisi, M.P.; Varani, K.; Spisani, S.; Lucente, G. Chemotactic peptides: fMLF-OMe analogues incorporating proline-methionine chimeras as $\mathrm{N}$-terminal residue. Bioorg. Med. Chem., 2006, 14, 2253-2265.

[25] Karanewsky, D.S.; Badia, M.C.; Cushman, D. W.; DeForrest, J. M.; Dejneka, T.; Lee, V. G.; Loots, M. J.; Petrillo, E. W. (Phosphinyloxy)acyl amino acid inhibitors of angiotensin converting enzyme. 2. Terminal amino acid analogs of (S)-1-[6-amino-2[[hydroxy(4-phenylbutyl)phosphinyl]oxy]-1-oxohexyl]-L-proline. J. Med. Chem., 1990, 33, 1459-1469.

[26] Shang, S.; Tan, Z.; Dong, S.; Danishefsky, S. J. An Advance in Proline Ligation. J. Am. Chem. Soc., 2011, 133, 10784-10786.

[27] Pollock, S.B.; Kent, S.B. An investigation into the origin of the dramatically reduced reactivityof peptide-prolyl-thioesters in native chemical ligation. Chem. Commun., 2011, 47, 2342-2344.

[28] Hinderaker, M.P.; Raines, R.T. An electronic effect on protein structure. Protein Sci., 2003, 12, 1188-1194.

[29] Choudhary, A.; Raines, R.T. Signature of $n \rightarrow \pi^{*}$ interactions in $\alpha$ helices. Protein Sci., 2011, 20, 1077-1081.

[30] Rüeger, H.; Benn, M.H. The preparation of (S)-3,4-dehydroproline from (2S,4R)-4-hydroxyproline. Can. J. Chem., 1982, 60, 29182920.
[31] Robinson, J.K.; Lee, V.; Claridge, T.D.W.; Baldwin, J.E.; Schofield, C.J. Synthesis of (2S, 3R, 4S), (2S, 3S, 4R)Epoxyprolines and Aminohydroxyprormes. Tetrahedron, 1998, 54 981-996.

[32] Durek, T.; Alewood, P.F. Preformed Selenoesters Enable Rapid Native Chemical Ligation at Intractable Sites. Angew. Chem. Int. Ed. Engl., 2011, 50, 12042-12045.

[33] Metanis, N.; Keinan, E.; Dawson, P.E. Traceless Ligation of Cysteine Peptides Using Selective Deselenization. Angew. Chem. Int. Ed. Engl, 2010, 49, 7049-7053.

[34] Caputo, R.; Dellagreca, M; de Paola, I.; Mastroianni, D.; Longobardo, L. Novel sulfur and selenium containing bis- $\alpha$-amino acids from 4-hydroxyproline. Amino Acids, 2010, 38, 305-310.

[35] Panday, S.K. Advances in the chemistry of proline and its derivatives: an excellent amino acid with versatile applications in asymmetric synthesis. Tetrahedron: Asymmetry, 2011, 22, 1817-1847.

[36] Wiśniewski, K.; Alagarsamy, S.; Galyean, R.; Tariga, H.; Thompson, D.; Ly, B.; Wiśniewska, H.; Qi, S.; Croston, G.; Laporte, R.; Rivière, PJ.; Schteingart, C.D. New, potent, and selective peptidic oxytocin receptor agonists. J. Med. Chem., 2014, 57, 5306-5317.

[37] Paradisi, M.P.; Mollica, A.; Cacciatore, I.; Di Stefano, A.; Pinnen, F.; Caccuri, A.M.; Ricci, G.; Duprè, S.; Spirito, A.; Lucente, G. Proline-glutamate chimeras in isopeptides. Synthesis and biological evaluation of conformationally restricted glutathione analogues. Bioorg. Med. Chem., 2003, 11, 1677-1683. 